\title{
CONSIDERAÇÕES SOBRE A OBRA MADONA COM MENINO E SÃO JOÃO BATISTA DA FUNDAÇÃO EVA KLABIN
}

Fernanda Marinho ${ }^{1}$

\section{Resumo}

Apesar de atualmente ser atribuída na Fundação Eva Klabin a Sandro Botticelli, a pintura Madona com Menino e São João Batista, possui uma autografia polêmica que também já circundou os nomes de Lorenzo di Credi e Filippino Lippi. Seu estilo predominantemente clássico traça uma forte relação com a tradição florentina do Renascimento. Apresenta uma notável qualidade pictórica, mas com as diversas restaurações e limpezas pelas quais passou, seus traços originais foram sendo encobertos, dificultando assim o seu estudo iconográfico e autográfico. A sua análise, portanto, visa prioritariamente a abordagem de uma discussão de possibilidades de autoria segundo aproximações estilísticas, relevando os nomes já sugeridos.

Palavras-chave: Atribuição; Botticelli; Florença; Renascimento; Restauração.

\begin{abstract}
:
Although it is currently attributed by Eva Klabin Foundation to Sandro Botticelli, the painting entitled Madonna with Child and Saint John the Baptist, has a controversial autography; a controversy similar to those ones once involving the names of Lorenzo Di Credi and Filippino Lippi. The predominantly classical style of the painting strongly indicates a relationship with the Florentine tradition of the Renaissance. The work is of remarkable pictorial quality, but having undergone many restorations and cleaning processes, its original lines were gradually covered, making it difficult to study its iconography and autography. Its analysis, therefore, aims primarily at discussing the possibilities of authorship based on stylistic similarities, with special emphasis on the names already suggested.
\end{abstract}

Key words: Attribution, Botticelli; Florence; Renaissance; Restoration.

\section{Introdução}

Pertencente ao acervo da Fundação Eva Klabin, a pintura Madona com Menino e São João Batista possui uma autografia polêmica. Atribuída atualmente pela Fundação ao pintor florentino Sandro Botticelli, já foram também propostos, sempre sob critérios exclusivamente estilísticos, os nomes de Lorenzo Di Credi e Filippino Lippi como prováveis autores da tela.

Adquirida pela colecionadora Eva Klabin Rapaport entre os anos de 1961 e 1965, a obra já sofreu no Brasil diversas restaurações que encobriram seus traços originais. Carente de documentações, a sua análise circunda, portanto, o campo das hipóteses e aproximações estilísticas. No entanto, sua qualidade pictórica é notável. Suas escolhas compositivas demonstram uma forte relação com a tradição clássica. A composição formal do quadro é organizada segundo uma divisão sistemática de seus elementos a fim de alcançar a proporção das partes e a harmonia das mesmas com o todo. O quadro é centralizado pela expressão serena de Maria, pela disposição equilibrada de seus personagens e pelo entrecruzamento de olhares no espaço: o Menino olha para São João Batista, que ajoelhado olha para Maria que tem seu olhar disperso.

${ }^{1}$ Universidade do Estado do Rio de Janeiro 
A feição aristocrática da Virgem (os traços finos de seu rosto, o queixo pontudo, a boca pequena, a testa alta) nos remete imediatamente ao círculo de Botticelli. Há neste personagem um parentesco com suas alegorias mitológicas ou mesmo com suas Madonas. No entanto, o mesmo motivo que aproxima a obra deste artista, traça também uma forte relação entre a mesma e Filippino Lippi: os traços do Menino são estilisticamente ligados às suas demais representações do mesmo personagem. Estes dois artistas compartilham muitas características pictóricas, já que Filippino Lippi era discípulo de Botticelli. Apesar da semelhança com os traços de Lorenzo Di Credi ser menos notória do que os demais artistas citados, a possibilidade de sua autoria também já foi levantada. Esta indefinição, no entanto, nos leva a cogitar a época histórica da obra: o Quattrocento Florentino, momento que congrega estes três artistas - uma possibilidade reforçada pela representação de São João Batista, o santo padroeiro de Florença.

Discutir sua autoria implica igualmente em falarmos sobre o seu estado de conservação e as restaurações que sofreu. Possui uma rachadura em seu suporte que corta o quadro ao meio verticalmente, o que faz com que necessite de constantes reparos. Sua última restauração foi em 2005, mas teve o seu tratamento iniciado com antecedência para uma exposição em 2004, que incluiu uma limpeza parcial para reduzir a desfiguração da camada de verniz e retocar a coloração antiga. Ao longo deste trabalho, percebeu-se que a sua última restauração, realizada devido a uma infestação de insetos, havia coberto uma grande área da pintura original.

Com tantos retoques, dificultou-se ainda mais o estudo da obra: o manto da Virgem perdeu volumetria; o seu véu e as auréolas douradas estão menos evidentes; o fundo inferior perdeu a nitidez, escondendo parcialmente a paisagem; além da pintura de um modo geral apresentar-se hoje mais escurecida.

Esta análise, portanto, aqui proposta procura acima de tudo traçar uma apreciação da obra em questão, revelando seu processo de restauro e as modificações pelas quais passou e levantando as possibilidades de autoria, sem ter o objetivo de chegar a uma conclusão rígida, mas sim a uma hipótese bem fundamentada.

\section{Madona com Menino e São João Batista: suas escolhas compositivas}

O tema da obra não se destaca em originalidade. A representação da Virgem sentada em primeiro plano com o Menino em seu colo é um topos visual do Quattrocento Florentino. Percebe-se, no entanto, que a perspectiva linear, tão enfatizada nesta época aparece aqui em segundo plano. Enquanto Alberti defendia a perspectiva como concretização visual da objetividade da beleza, nesta obra ela não parece ser explorada como tal. Não se apresenta como forma definidora da estrutura de sua representação, mas sim apenas como um elemento de sua composição global. Esta característica, não estaria, no entanto, afastando a nossa aproximação da obra à sua época estimada, pois houve artistas florentinos que abdicaram da perspectiva com tal finalidade, como por exemplo, Botticelli e Filippino Lippi.

Daniel Arasse em seu texto "A Maneira de Botticelli", afirmou: "The use that Botticelli made of perspective betrays an equally determined and singular position". . Refere-se, principalmente aos seus trabalhos em painéis em que traça sucessões de localizações narrativas, contrariando Alberti que defendia a perspectiva como organismo unitário que

2 "O uso que Botticelli fez da perspectiva revela uma posição igualmente determinada e singular". ARASSE, Daniel. "Botticelli's Manner". In: Botticelli. From Lorenzo the Magnificent to Savonarola. Milano: Skira Editore S.p.A., 2003; pg 18. 
integra a história. Percebe-se que o quadro em questão não emprega nem a perspectiva defendida por Alberti e nem esta escolhida por Botticelli na execução de seus painéis. Ela se faz mais presente na paisagem de fundo, que não parece apresentar relevância na composição final, sendo apenas mais um elemento narrativo.

O mesmo ocorre com Filippino Lippi. Este relaciona o tamanho de suas figuras de acordo com a importância que exercem na pintura. Já Lorenzo Di Credi se diferencia destes dois, pois o seu investimento na perspectiva é mais efetivo, como notado em Anunciação, onde cria uma "barmonious architecture" ${ }^{3}$. Apesar dessa diferença formal entre Lorenzo e a pintura em questão, há um elemento que os unifica: um suporte que sugere ser uma larga coluna onde Maria se encosta. Esta se faz presente na maioria de suas representações da Virgem, característica não notada em Botticelli ou Filippino.

Assim como a perspectiva linear, Alberti chamava atenção para o emprego da "linha invisivel", ou seja, aquela que valoriza a volumetria e o relevo dos corpos que com o objetivo de criar ilusão, não deveria ser evidenciada no trabalho finalizado. Neste sentido, Madona com Menino e São João Batista não parece investir muito na construção do volume corporal. Suas figuras se aproximam mais de um resquício da forma gótica, assim como as figuras de Botticelli e de maneira menos enfática, Filippino Lippi.

Apesar de ser conhecido como um dos maiores seguidores das teorias de Alberti, Botticelli subverteu o mesmo em diversos sentidos, não escondendo o seu caráter anticlássico dentro de sua estrutura clássica: reforça a linha que contorna as figuras tanto externa quanto internamente, demarcando os limites corporais, como explicado por Arasse:

$[\ldots .$.$] it is the deployment of this line across the surface, circulating and looping,$ modulated, from one figure to another, that ensures the rhythmic coordenation of the elements of the representation, with the drapery and hair in movement playing a decisive role dynamic connection ${ }^{4}$.

Apesar da obra analisada se aproximar de Botticelli no que se refere ao pouco investimento na volumetria, eles se afastam, contudo, quanto ao acabamento finalizado da linha. Enquanto Botticelli emprega a sua linha mais em função da produção de ritmos do que da formação de volume, aqui a linha se apresenta menos dinâmica e mais tímida, como se nota no dorso de São João Batista, nas mãos de Maria, no seu véu e no braço do Menino.

Este trabalho de discussão de autografia acaba inevitavelmente realizando uma comparação entre os artistas analisados. Supõe-se que estes apresentem características em comum para que possam ser considerados autores de uma mesma obra. No entanto, apesar dessa comparação aproximada, Wölfflin na introdução de seu livro Conceitos Fundamentais da História da Arte, separa a maneira de Botticelli da de Lorenzo Di Credi. Enquanto as "linhas impetuosas" do primeiro criam uma "forma agitada" e "animação peculiar", a "modelação cautelosa" do segundo produz uma sensação de objeto em repouso. Sua forma é concebida em volumes, procura uma beleza ligada à postura e proporção,

\footnotetext{
3 "arquitetura harmoniosa"; Uffizi; FOSSI, Gloria (editora). Uffizi - art, history, collections. Florence: Giunti Editore S.p.A., 2004; pg 296.

4 "[...] é a disposição da linha sobre a superficie, que circunda e modula, de uma figura a outra, que garante a coordenação ritmica dos elementos da representação, com o drapejamento e o movimento do cabelo constituindo uma total decisão de conexão dinâmica"; ARASSE, Daniel. "Botticelli's Manner". In: Botticelli. From Lorenzo the Magnificent to Savonarola. Milano: Skira Editore S.p.A., 2003; pg 20.
} 
enquanto a de Botticelli estaria vinculada ao ideal de forma ("esbeltera da figura ereta"). Neste sentido, a pincelada de Lorenzo estaria mais de acordo com aquela encontrada no quadro da Fundação: há uma ausência de movimento, uma energia menos ativa que a de Botticelli e Filippino. No entanto, existe um risco nesta afirmação, pois uma vez que este quadro já foi muito restaurado, deveríamos considerar supostas perdas em seus traços originais. A linha tão evidente em Botticelli não se manteria viva com tantas camadas de tinta, como ocorreu com o manto azul da Virgem, a área mais modificada pela restauração na pintura como um todo. Provavelmente a nova camada de tinta sobre o manto utilizou o azurita, substância que escurece quando misturado ao óleo ou verniz. O seu drapejamento original perdeu-se por inteiro. Hoje vemos uma grande área escurecida onde o Menino parece flutuar. E este talvez fosse um outro motivo de aproximação da obra a Lorenzo, já que foi um grande pesquisador de drapejamentos, absorvendo as influências de Leonardo da Vinci. Além da sua volumetria, o manto perdeu qualidade em dois dos seus três adornamentos dourados. Apenas a estrela localizada no ombro da Virgem, não foi retocada.

O véu de Maria foi outro elemento prejudicado na restauração. A delicadeza do traço, sua transparência e a idéia de movimento não foram tão perdidas, principalmente onde envolve a sua cabeça. No entanto, a parte inferior que repousa sobre o seu ombro ficou menos evidente e com isso escondeu um importante símbolo iconográfico: o gesto da mão esquerda do Menino que brinca com o véu, uma prefiguração do sacrifício.

\section{Símbolos iconográficos}

O estudo iconográfico das obras está sempre sendo renovado. A leitura que fazemos de seus elementos compositivos é variável, pois sabemos que as imagens são signos abertos às interpretações. A utilização de elementos simbólicos tornou-se uma prática nas representações bíblicas do Renascimento. Podemos reparar com freqüência a presença de romãs, cerejas, livros, coroas de espinhos, rosas, que aludem à beleza ou pureza da Virgem, à Paixão de Cristo, à redenção da humanidade. Segundo a tradição judaica, quando o homem atinge a sua puberdade (Bar Mitzva), recebe um pano sagrado que simboliza o seu ingresso no mundo religioso, no caso de Cristo conhecido como o manto sagrado. Este mesmo pano lhe envolverá na sua morte. O véu, portanto, seria um símbolo epifânico da mortalha de Cristo, uma anunciação de seu sacrifício pela humanidade.

Combinado à estrutura representativa da obra que apresenta personagens bíblicos, esta alegoria sacrifical realça a idéia principal da pintura: a crença na divindade e o desejo à sua adoração. A idéia de sacralidade é reforçada nas auréolas douradas, na cruz de São João Batista, no manto da Virgem e também na paisagem de fundo. A balaustrada que divide o espaço de Maria do jardim cria uma atmosfera de proteção ("hortus conclusus"), abriga a Virgem num ambiente reservado, traçando uma relação direta com a sua virgindade.

Há em seu manto azul uma estrela localizada no ombro esquerdo. Este elemento pode estar relacionado às antigas divindades maternas, como Afrodite, Urânia e Mitra que usam um manto estrelado como sinal de pertencerem aos céus. Assim, a Virgem estaria sendo reverenciada como uma rainha celeste. Ou então faz referência à Imaculada Conceição que foi coroada com doze estrelas.

Reforçando a fé católica há ao fundo esquerdo da paisagem um indício de arquitetura que poderíamos entender como uma ruína. Este elemento, juntamente com a 
representação de Jesus ainda criança, aludem fortemente à idéia do fim do paganismo, anunciando o nascimento do cristianismo.

\section{Considerações finais}

A finalização deste trabalho permeia um campo instável. Não objetiva encerrar a discussão levantada, mas de uma forma menos pretensiosa dar continuidade a ela criando possibilidades interpretativas. A ligação da obra com Botticelli é aparente, mas não o suficiente para afirmamos a sua autoria.

Botticelli trabalhou muito por encomenda, antes de cair no esquecimento no final de sua carreira. Apesar das encomendas restringirem de certa forma a criatividade do artista, quanto ao tema e a maneira de executá-lo, Botticelli não se rendeu às exigências. Diferente de seu discípulo Filippino Lippi que desenvolveu peculiar capacidade de modificar seu estilo de acordo com cada cliente, ele manteve seus traços e sua pesquisa pictórica praticamente imutáveis.

Não se ocupou apenas das grandes produções, mas também de pequenas pinturas da Madona com Menino para devoções particulares. Contou com muitos ajudantes em seu ateliê. Por haver uma ausência de desarmonia em suas obras, podemos cogitar que a sua técnica deveria ser facilmente dominada pelos seus ajudantes e discípulos, uma vez que não conseguimos apontar um traço ou outro que se desequilibre da composição geral. Assim sendo, podemos questionar mais uma vez a atribuição atual do quadro da Fundação, não descartando a sua ligação com o mestre florentino, mas levantando a possibilidade desta obra estar mais inserida no perfil das obras de atelier de Botticelli ou de Filippino Lippi.

There certainly are more fake than genuine Botticelli Madonnas around, and far too many have been attributed to the master sometimes on no sounder evidence than the opinion of a dealer. Since there are no documents for any of Botticelli's genuine Madonnas, it is often more difficult to disprove such an attribution (particularly if the work has been sold as a 'Botticelli' and fetched a correspondingly high price) than to prove it ${ }^{5}$.

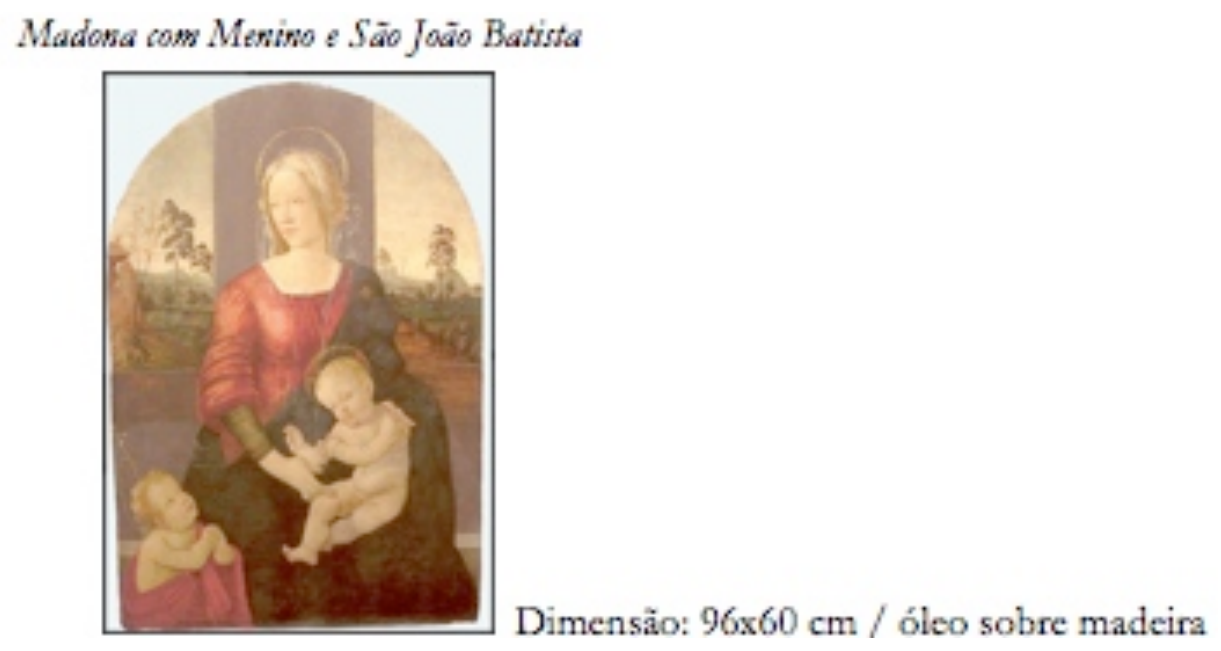

5 "Certamente, há mais Madonas de Botticelli falsificadas do que originais, e muitas têm sido atribuidas ao mestre, algumas vezes sem uma comprovação mais sólida do que a opinião do merchant. Como não bá documentação sobre qualquer uma das Madonas autênticas de Botticelli, é mais difícil contestar tal atribuição (particularmente se o trabalbo foi vendido como um 'Botticelli' e cobrado o alto preço correspondente) do que prová-la." L. D. et ETTLINGER, Helen S. "Religious Paintings". In: Botticelli. London: Thames and Hudson Ltd, 1976; pg 80. 


\section{Bibliografia}

ARASSE, Daniel. "Botticelli's Manner". In: Botticelli. From Lorenzo the Magnificent to Savonarola. Milano: Skira Editore S.p.A., 2003.

ARGAN, Giulio Carlo. Clássico Anticlássico: o Renascimento de Brunelleschi a Bruegel. São Paulo: Companhia das Letras, 1999.

BLUNT, Anthony. Teoria Artística na Itália 1450-1600. São Paulo: Cosac \& Naify Edições, 2001.

CHEVALIER, Jean. Dicionário de Símbolos. Rio de janeiro: José Olympio, 1998.

FOSSI, Gloria (editora). Uffizi - art, history, collections. Florence: Giunti Editore S.p.A., 2004.

KROEGEL, Alessandra Galizzi. "The Figure of Mary in Botticelli's Art”. In: Botticelli. From Lorenzo the Magnificent to Savonarola. Milano: Skira Editore S. p. A., 2003.

L. D. et ETTLINGER, Helen S. "Religious Paintings". In: Botticelli. London: Thames and Hudson Ltd, 1976.

LEMAÎTRE, Alain J. Florence and the Renaissance - The Quattrocento. Paris: Éditions Pierre Terrail, 1993.

LONGHI, Roberto. Breve mas verídica história da pintura italiana. São Paulo: Cosac \& Naify, 2005.

LUKER, Manfred. Dicionário de Simbologia. São Paulo: Martins Fontes, 1997.

MACKENZIE, John L. Dicionário Bíblico. São Paulo: Editora Paulinas, 1983.

WÖLFFLIN, Heinrich. Conceitos Fundamentais da História da Arte. São Paulo: Martins Fontes, 2000. 